\title{
Neuroprotection by Nicotine in Mouse Primary Cortical Cultures Involves Activation of Calcineurin and L-Type Calcium Channel Inactivation
}

\author{
Tanya R. Stevens, ${ }^{1}$ Stefan R. Krueger, ${ }^{2}$ Reiko M. Fitzsimonds, ${ }^{2}$ and Marina R. Picciotto ${ }^{1}$ \\ Departments of ${ }^{1}$ Psychiatry and ${ }^{2}$ Cellular and Molecular Physiology, Yale University School of Medicine, New Haven, Connecticut 06508
}

\begin{abstract}
Regulation of intracellular calcium influences neuronal excitability, synaptic plasticity, gene expression, and neurotoxicity. In this study, we investigated the role of calcium in mechanisms underlying nicotine-mediated neuroprotection from glutamate excitotoxicity. Neuroprotection by nicotine in primary cortical cultures was not seen in knock-out mice lacking the $\beta 2$ subunit of the nicotinic acetylcholine receptor (nAChR). Neuroprotection was partially blocked in wild-type cultures by $\alpha$-bungarotoxin, an antagonist of the $\alpha 7 \mathrm{nAChR}$ subtype, suggesting a potential cooperative role for these subtypes. Pretreatment with nicotine decreased glutamate-mediated calcium influx in primary cortical cultures by $41 \%$, an effect that was absent in cultures from knock-out mice lacking the $\beta 2$ subunit of the nAChR. This effect was dependent on calcium entry through L-type channels during nicotine pretreatment in wild-type cultures. The ability of nicotine to decrease glutamate-mediated calcium influx was occluded by cotreatment with nifedipine during glutamate application, suggesting that nicotine pretreatment decreased subsequent activity of L-type calcium channels. Treatment with the calcineurin antagonists FK506 and cyclosporine during pretreatment eliminated both nicotine-mediated neuroprotection and the effects of nicotine on L-type channels. We conclude that neuroprotective effects of nicotine in cortical neurons involve both $\beta 2$ - and $\alpha 7$-containing nAChRs, activation of calcineurin, and decreased intracellular calcium via L-type channels.
\end{abstract}

Key words: calcium imaging; cell death; glutamate; FK506; nifedipine; nicotinic acetylcholine receptors

\section{Introduction}

Nicotine, the primary active agent in tobacco smoke, is protective against neurotoxicity initiated by excitatory amino acids in vivo (Borlongan et al., 1995) and in vitro (Akaike et al., 1994; Marin et al., 1994; Dajas-Bailador et al., 2000). In addition, smoking is negatively correlated with development of the neurodegenerative disorders Parkinson's and Alzheimer's disease (Fratiglioni and Wang, 2000). The primary targets for nicotine in the CNS are the neuronal nicotinic acetylcholine receptors (nAChRs), a diverse family of ligand-gated ion channels that are associated with gene transcription, neurotransmitter release, addiction, and neuroprotection (Jones et al., 1999; Picciotto et al., 2001; Rezvani and Levin, 2001).

The identity of the nAChR subtype(s) responsible for the protective effects of nicotine is controversial. In hippocampal neurons, nicotine-induced neuroprotection is blocked by $\alpha$-bungarotoxin ( $\alpha$-BTX), a specific antagonist of $\alpha 7$ subunitcontaining nAChRs (Dajas-Bailador et al., 2000). However, in cortical neurons, $\alpha 4 / \beta 2^{\star}$ nAChRs appear to be involved in

\footnotetext{
Received June 26, 2003; revised Sept. 11, 2003; accepted Sept. 12, 2003.

This work was supported by grants from the Alzheimer's Association and the National Institutes of Health (NIH) (DA00436, DA10455, and DA14241). R.M.F. was supported by grants from NIH (MH-59800) and the Burroughs Wellcome Fund. We thank Eva Yang and Annette Kolar for assistance with primary neuronal cultures and other technical advice.

Correspondence should be addressed to Marina R. Picciotto, Department of Psychiatry, Yale University School of Medicine, 34 Park Street, Third Floor Research, New Haven, CT 06508. E-mail: marina.picciotto@yale.edu. Copyright $\odot 2003$ Society for Neuroscience 0270-6474/03/2310093-07\$15.00/0
}

nicotine-mediated protection against glutamate excitotoxicity (Akaike et al., 1994), although $\alpha 7$-type nAChRs might also contribute to these effects (Kaneko et al., 1997; Kihara et al., 1998). Furthermore, $\beta 2 \mathrm{nAChR}$ subunit knock-out mice $(\beta 2-/-)$ that lack high-affinity nicotine binding sites (Picciotto et al., 1995) show increased cortical atrophy during aging (Zoli et al., 1999) and increased cortical susceptibility to ibotenic acid lesion (Laudenbach et al., 2002), suggesting that endogenous neuroprotection is reduced as a result of loss of $\beta 2$ subunit-containing nAChRs. The signal transduction mechanism(s) underlying nAChR-mediated neuroprotection in all cell types remains unclear.

One potential mechanism for this effect is nicotinic modulation of glutamate-mediated increases in intracellular calcium $\left(\mathrm{Ca}^{2+}\right)$ levels. Maintenance of intracellular $\mathrm{Ca}^{2+}$ homeostasis is crucial for cell survival and synaptic plasticity. The site, magnitude, and kinetics of $\mathrm{Ca}^{2+}$ changes determine the biological consequences of $\mathrm{Ca}^{2+}$ signaling in the neuron (Shieh et al., 1998; Tao et al., 1998; Shoop et al., 2002). Because nAChRs can increase intracellular $\mathrm{Ca}^{2+}$ directly (McGehee and Role, 1996; Girod et al., 2003) or indirectly through activation of voltage-gated $\mathrm{Ca}^{2+}$ channels or release of $\mathrm{Ca}^{2+}$ from intracellular stores (Tsuneki et al., 2000; Chang and Berg, 2001), we hypothesized that one mechanism underlying nicotine-induced protection against excitotoxicity could be modulation of glutamate-mediated $\mathrm{Ca}^{2+}$ entry. We hypothesized further that one mechanism that could be affected by low levels of $\mathrm{Ca}^{2+}$ entry because of nAChR activation 
could be activation of the high-affinity $\mathrm{Ca}^{2+}$-dependent phosphatase calcineurin, which could, in turn, modulate $\mathrm{Ca}^{2+}$ dependent signaling pathways that mediate nicotine neuroprotection. In this paper, we demonstrate that nicotine pretreatment alters $\mathrm{Ca}^{2+}$ influx in cortical neurons, and that $\beta 2$ subunitcontaining nAChRs are essential for this effect. The mechanisms elucidated have implications for neuroprotection but also for the effects of nicotine on synaptic plasticity, learning, and memory.

\section{Materials and Methods}

All animal procedures were conducted in strict accordance with National Institutes of Health Care and Use of Laboratory Animals Guidelines and were approved by the Yale Animal Care and Use Committee. Reagents were purchased from Sigma (St. Louis, MO) unless stated otherwise.

Cell culture. Mixed cortical cultures were made from wild-type or $\beta 2-/-$ fetal mice [embryonic day 16 (E16)-E18]. Neurons were dissociated by incubating minced cortices in PDD $[0.01 \%$ papain (Worthington, Freehold, NJ), 0.1\% dispase (Roche Products, Hertforshire, UK), and $0.01 \%$ DNase (Sigma)] in HBS [composed of the following (in mM): 10 HEPES, 10 glucose, $140 \mathrm{NaCl}$, and $5 \mathrm{KCl}, \mathrm{pH} \mathrm{7.4]} \mathrm{for} 15 \mathrm{~min}$ at $37^{\circ} \mathrm{C}$. Cells were resuspended in Neurobasal media supplemented with $5 \%$ FBS, B27 supplement (Invitrogen, San Diego, CA), sodium pyruvate, glutamine, and 2 mM HEPES. Dissociated cortical neurons were cultured on poly-L-lysine-laminin-coated $15 \mathrm{~mm}$ glass coverslips at $8 \times 10^{4}$ to $1.0 \times 10^{5} \mathrm{cells} / \mathrm{ml}$. Cells were maintained at $37^{\circ} \mathrm{C}$ in a humidified atmosphere of $5 \% \mathrm{CO}_{2}$ and fed once per week. Mixed cortical cultures were used for $\mathrm{Ca}^{2+}$ imaging and cell toxicity experiments between days 11 and 13 after plating. Glial cells were present in the cultures but were $<10 \%$ of the overall population. The few neurons that grew on top of glial cells were excluded from the imaging studies because accurate changes in fluorescence would not be obtained. $\beta 2-/-$ cortical cultures were obtained from mice that were back-crossed $>14$ generations onto the C57BL/6J background.

$\mathrm{Ca}^{2+}$ imaging. After nicotine or HBS pretreatment, cells were loaded with $2 \mu \mathrm{M}$ fluo-3 (Molecular Probes, Eugene, OR) for $10 \mathrm{~min}$ at room temperature in HBS $0 / 0$ and washed twice with HBS 2/1 (HBS with $2 \mathrm{~mm}$ $\mathrm{CaCl}_{2}$ and $1 \mathrm{~mm} \mathrm{MgCl}_{2}$ ). The dye was not saturated under the conditions used here because raising the extracellular $\mathrm{Ca}^{2+}$ level from 2 to $3 \mathrm{~mm}$ resulted in a significant increase in the calcium signal (data not shown). Although this experiment shows that fluo-3 was not saturated with calcium under conditions of glutamate stimulation, fluo- 3 emission may be in a sublinear range under these conditions; thus our results must be considered only semiquantitative. In the time course study, one group of cultures was treated with nicotine for 5-10 min after loading. Inhibitors [in $\mu \mathrm{M}$ : 100 APV, 50 nifedipine, 200 cadmium, 50 2,3-dihydroxy-6-nitro-7sulfonyl-benzo[f]quinoxaline (NBQX), or 50 dantrolene] were added to the loading solution after pretreatment with nicotine or HBS for $1 \mathrm{hr}$ and were present throughout the experiment. In experiments blocking effects of nicotine during the $1 \mathrm{hr}$ preincubation period, 100 nM FK506 (Research Biochemicals, Natick, MA) was added 10 min before the $1 \mathrm{hr}$ incubation and washed out before glutamate treatment. $\alpha$-BTX was added 20 min before addition of nicotine or $\mathrm{HBS}$. To remove $\mathrm{Ca}^{2+}$ during nicotine pretreatment, cells were incubated in $\mathrm{HBS}\left(0 \mathrm{CaCl}_{2}, 3 \mathrm{mM} \mathrm{MgCl}\right)$ with or without $10 \mu \mathrm{M}$ nicotine for $1 \mathrm{hr}$, loaded, and assayed for glutamate response in HBS (2.1). Solutions were exchanged using heated bath perfusion $\left(37^{\circ} \mathrm{C}\right)$ with a flow rate of $2 \mathrm{ml} / \mathrm{min}$ in a volume of $\sim 75 \mu \mathrm{l}$. All images were obtained using a $20 \times$ objective on a TE300 inverted microscope (Nikon, Tokyo, Japan) equipped with a cooled CCD camera (orca; Hamamatsu, Bridgewater, NJ). Acquired images were adjusted for the level of background intensity, digitally colored, and analyzed using IPLab software (Scanalytics, Fairfax, VA). Images of the fluo-3 loaded cells were obtained over a period of $1 \mathrm{~min}$ at $2 \mathrm{sec}$ intervals. Each experiment was repeated a minimum of three times with comparable results.

Quantitation. Change in fluorescence was quantitated as described previously (Vijayaraghavan et al., 1992). $\mathrm{Ca}^{2+}$ influx was determined as the change from basal levels after glutamate stimulation [(stimulated level - basal level)/basal level of fluorescence]. Stacked images from 0 to $60 \mathrm{sec}$ were collected for each experiment. A region including the entire soma of an individual neuron was selected, and the change in pixel density was averaged over this area for every frame. A change in basal fluorescence was seen in studies using $200 \mu \mathrm{M}$ cadmium (average level, $45.0 \pm 8.9$ ), as has been reported in studies from other laboratories (Sharma and Vijayaraghavan, 2001). No change in basal fluorescence was seen for any other treatments (wild-type cultures pretreated with HBS or nicotine, average basal level of fluorescence $21.79 \pm 11.2$ and $22.38 \pm$ 12.5 , respectively; $\beta 2-/-$ cultures pretreated with HBS or nicotine, average basal level of fluorescence $26.56 \pm 7.9$ and $26.33 \pm 8.6$, respectively). On average, $9-12$ cells were examined per condition for each culture. Change in fluorescence was determined for each cell and averaged across cells in each culture. These studies were conducted in at least three different cultures, and an overall average from each culture was plotted for each graph. $n$ represents the number of cultures used for each experiment.

Assessment of neurotoxicity. For cell-death assays, nicotine was added to the media to a final concentration of $10 \mu \mathrm{m}$. The same volume of HBS 2.1 was added to control cultures, and cells were incubated for $1 \mathrm{hr}$ at $37^{\circ} \mathrm{C}$ in a humidified atmosphere of $5 \% \mathrm{CO}_{2}$. In experiments using FK506, the drug was added $10 \mathrm{~min}$ before nicotine or HBS preincubation. Media containing $100 \mu \mathrm{M}$ glutamate was added after preincubation, and cultures were assessed for cell death $18-20 \mathrm{hr}$ after the initiation of glutamate treatment. To minimize cell death attributable to perturbation of the cultures, media were not changed once glutamate was added. In control cells, the same volume of HBS 2.1 was added instead of glutamate. Cells were treated with $0.16 \mathrm{~mm}$ calcein-AM-0.36 mm ethidium homodimer in HBS 2.1 for $40 \mathrm{~min}$ at room temperature. Live cells were stained green throughout the soma, and projections and dead cells had red staining only in the nucleus or highly punctate green staining. Neurotoxicity was calculated as percentage survival [live cells/(live + dead cells)], and these values were expressed relative to the percentage survival of control cells. Four to six coverslips were examined per treatment, and a total of 10-15 randomly selected fields ( $10 \times$ objective) were captured using IPLab software. At least 200 cells were counted per condition, and each experiment was repeated in at least four different cultures.

Statistical analysis. Fluorescence measurements are reported as change in fluorescence over baseline. Data points were normalized and expressed as mean \pm SEM. All data were analyzed using repeated-measures ANOVA. The peak values for each curve were used for ANOVA (at least five time points were used). Post hoc analyses were conducted when appropriate using the least significant difference (LSD) test. $p<0.05$ was considered statistically significant.

\section{Results}

Primary cortical cultures from wild-type or $\beta 2-/-$ mice were used to examine nicotine-mediated neuroprotection. A combination of calcein-AM and ethidium homodimer was used to visualize live and dead neurons after glutamate-induced excitotoxicity (Fig. 1a,c). The number of live cells and the percentage of dead cells were equivalent between wild-type and $\beta 2-/-$ cultures treated with glutamate alone. Nicotine pretreatment significantly increased viability from 49 to $74.5 \%$ after glutamate treatment in wild-type cultures (Fig. $1 b$ ) but resulted in no change in cell death in $\beta 2-/-$ cultures (Fig. $1 d$ ), suggesting that highaffinity $\mathrm{nAChRs}$ are necessary for the neuroprotective effects of nicotine in cortical cultures. The $\alpha 7$-selective antagonist $\alpha$-BTX partially blocked nicotine-mediated neuroprotection in wildtype cultures but had no effect in $\beta 2-/-$ cultures, suggesting that cooperative effects of $\alpha 7$ and $\beta 2$ subunit-containing nAChRs might mediate the protective effect of nicotine in wild-type neurons (Fig. 1e,f).

To determine the cellular mechanism(s) responsible for the protective effect of nicotine, the high-affinity $\mathrm{Ca}^{2+}$-sensitive dye fluo-3 was used to measure glutamate-mediated $\mathrm{Ca}^{2+}$ influx in neurons. Similar experiments were performed using the lowaffinity $\mathrm{Ca}^{2+}$-sensitive dye BTC, but by using this dye, the changes in fluorescence observed during glutamate treatment 
a

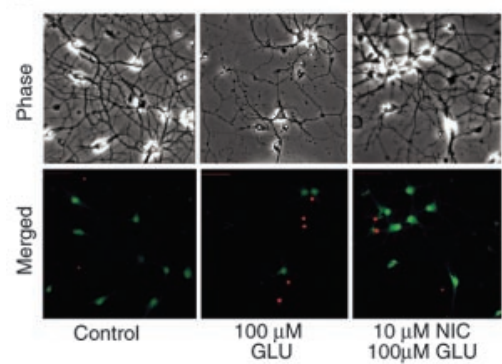

C
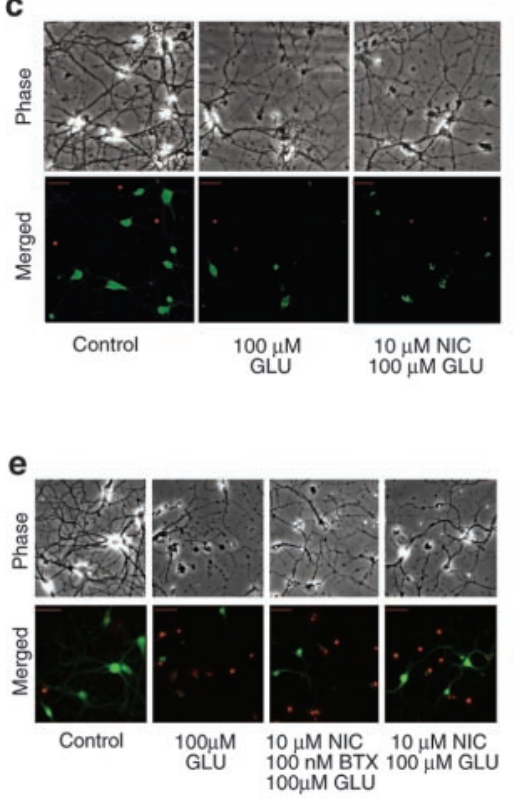

b

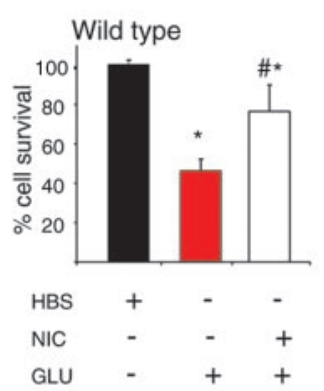

d

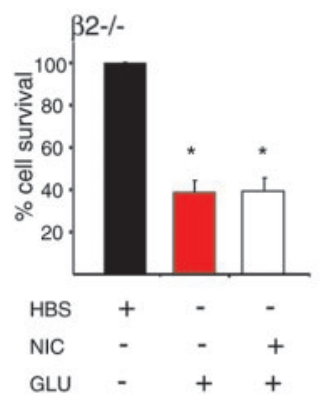

f

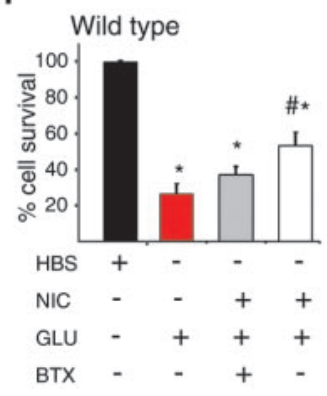

Figure 1. Nicotine-mediated neuroprotection against glutamate toxicity is abolished in primary cortical cultures from $\beta 2-/-$ mice. $a$, Phase pictures and merged fluorescence images of calcein-AM and ethidium-stained cells demonstrate a reduction in live cells (green) and an increase in dead cells (red) in glutamate-treated cultures. NIC, Nicotine; GLU, glutamate. b, Glutamate treatment reduced cell survival $(49 \%)$, and nicotine protected neurons from glutamate-mediated cell death $(74.5 \% ; n=7)$. c, Phase pictures and merged images from $\beta 2-/-$ cultures demonstrate that nicotine is not protective in the absence of high-affinity nAChRs. $d$, In cultures from $\beta 2-/-$ mice, glutamate significantly reduced cell survival (38.67\%) even after pretreatment with $10 \mu \mathrm{m}$ nicotine (39.45\%) $(p<0.005 ; n=5)$. e, Phase pictures and merged images from wild-type cultures show that coincubation of $\alpha$-BTX with nicotine resulted in an intermediate cell death between the glutamate and nicotine. $f$, In wildtype cultures, coincubation of BTX and nicotine resulted in an intermediate $36.94 \%$ survival compared with glutamate (26.50\%) and $10 \mu \mathrm{m}$ nicotine $(52.22 \% ; n=5)$. Asterisks indicate that cell survival after both glutamate treatment and nicotine pretreatment is statistically different from control $(p<0.05)$. Number signs indicate that cell survival in nicotine and glutamate-treated cultures is statistically different from survival of cultures treated with glutamate alone ( $p<0.05 ;$ LSD post hoc test). Data are shown as mean \pm SEM.

were too small to allow reliable detection of changes in $\mathrm{Ca}^{2+}$ levels (data not shown). Cells were phase-bright and well differentiated as shown by extensive dendritic outgrowth (Fig. 2a). Cultures were preincubated for $1 \mathrm{hr}$ with either control media (HBS) or $10 \mu \mathrm{M}$ nicotine and then stimulated with $100 \mu \mathrm{M}$ glutamate for $10 \mathrm{sec}$. Glutamate stimulation induced a substantial increase in intracellular $\mathrm{Ca}^{2+}$ levels that decreased by $41 \%$ after pretreatment with nicotine $(p<0.00001)$ (Fig. $2 b)$. Coincubation with nicotine and glutamate for $10 \mathrm{sec}$ was ineffective in altering $\mathrm{Ca}^{2+}$ influx; however, nicotine application 5-10 min

a

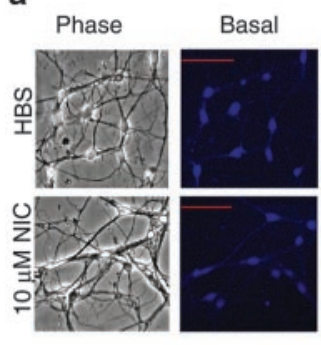

C
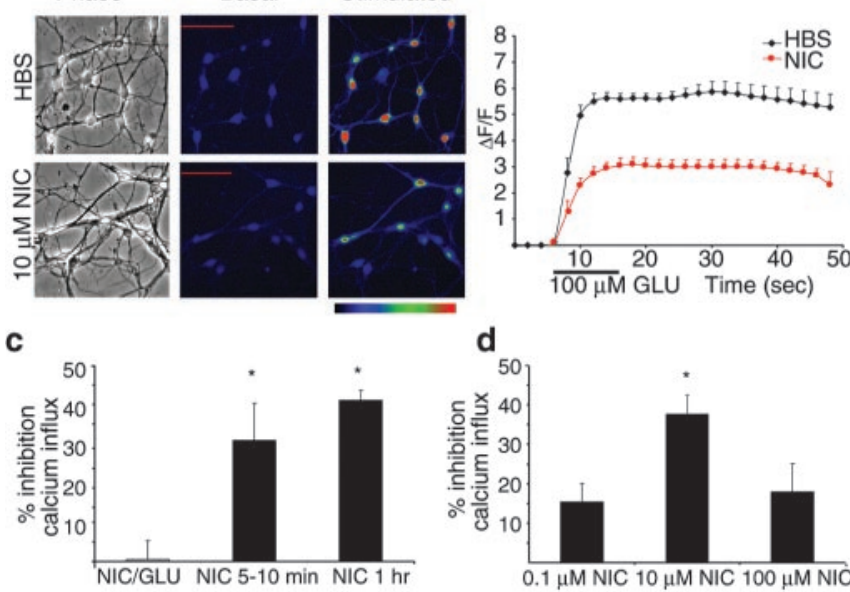

d

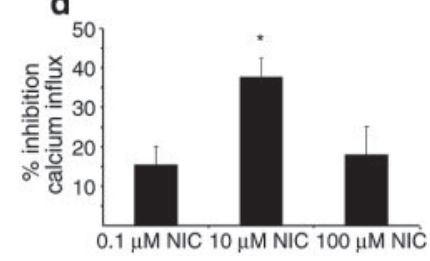

Figure 2. Nicotine pretreatment decreases glutamate-mediated $\mathrm{Ca}^{2+}$ entry into cortical primary cultured neurons. $a$, Examples of $\left[\mathrm{Ca}^{2+}\right]$ measurements in cortical neurons using fluo-3. NIC, Nicotine. Shown are neurons pretreated for $1 \mathrm{hr}$ with either HBS (top) or $10 \mu \mathrm{M}$ nicotine (bottom), at rest (basal), or during application of $100 \mu \mathrm{m}$ glutamate (stimulated). Phase contrast images of the respective cells are shown on the left. Scale bar, $50 \mu \mathrm{m}$. $b$, Quantitation of glutamate-mediated $\mathrm{Ca}^{2+}$ entry into neurons, with or without nicotine pretreatment $(n=7)$. GLU, Glutamate. c, Time course of nicotine-induced decrease in glutamatemediated $\mathrm{Ca}^{2+}$ influx. A significant decrease in $\mathrm{Ca}^{2+}$ influx was observed after 5-10 min, but maximal reduction in $\mathrm{Ca}^{2+}$ influx was observed after $1 \mathrm{hr}$ of nicotine treatment. $d$, Doseresponse relationship for the ability of nicotine pretreatment to reduce glutamate-mediated $\mathrm{Ca}^{2+}$ entry $(n=4)$. Maximal inhibition (41\%) occurred with $10 \mu \mathrm{m}$ nicotine. Percentage inhibition was calculated as [(control - treatment)/control] value of $\mathrm{Ca}^{2+}$ influx. ${ }^{*} p<0.05$. Data are shown as mean \pm SEM.

before glutamate treatment caused a significant and sustained decrease in glutamate-mediated $\mathrm{Ca}^{2+}$ influx (Fig. 2c). The maximal effect was observed with $1 \mathrm{hr}$ of nicotine pretreatment. In addition, dose-response experiments established that a maximal effect on glutamate-mediated $\mathrm{Ca}^{2+}$ entry was achieved at $10 \mu \mathrm{M}$ nicotine (Fig. $2 d$ ), so all additional experiments were performed at this dose.

The ability of nicotine to increase intracellular $\mathrm{Ca}^{2+}$ was essential for its effects on glutamate-mediated $\mathrm{Ca}^{2+}$ entry. Cells were incubated with either HBS containing no calcium (HBS 0.3) or $10 \mu \mathrm{M}$ nicotine in HBS 0.3 for $1 \mathrm{hr}(3 \mathrm{~mm} \mathrm{MgCl}$ was used to counteract the effect of lowering extracellular $\mathrm{Ca}^{2+}$ on resting membrane resistance and excitability) and were then assayed for $\Delta F / F$. Removal of $\mathrm{Ca}^{2+}$ during nicotine exposure abolished the ability of nicotine to modulate glutamate-mediated $\mathrm{Ca}^{2+}$ influx (Fig. 3a). Fluorescence appears to decrease more rapidly in cells pretreated in calcium-free medium, which could represent increased susceptibility to cell death in cultures after this destabilizing treatment, but this difference was not significant. The ability of nicotine to increase intracellular calcium was also assessed. A $10 \mu \mathrm{M}$ concentration of nicotine did not produce increases in $\mathrm{Ca}^{2+}$ that could be resolved under the conditions used, although a higher concentration of nicotine $(1 \mathrm{~mm})$ did produce a small increase in $\mathrm{Ca}^{2+}$ when a higher extracellular calcium concentration was used (data not shown).

Several previous studies have suggested that voltage-gated $\mathrm{Ca}^{2+}$ channels are critical for the effects of nAChR activation in many cell types (Damaj et al., 1993; Chang and Berg, 2001; Shoop et al., 2001). We therefore hypothesized that voltage-gated $\mathrm{Ca}^{2+}$ channel activity occurring during nicotine pretreatment was critical for the subsequent decrease in glutamate-mediated 
a

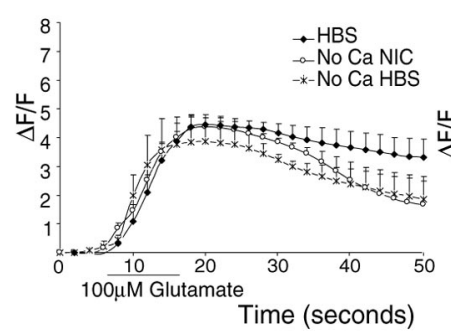

b

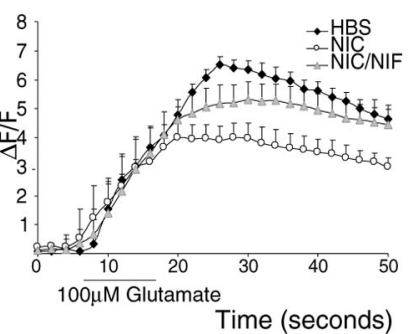

Figure 3. The effect of nicotine on glutamate-mediated $\mathrm{Ca}^{2+}$ entry is dependent on the presence of $\mathrm{Ca}^{2+}$ during nicotine pretreatment. $a$, The effect of nicotine on glutamatemediated $\mathrm{Ca}^{2+}$ influx was abolished when extracellular $\mathrm{Ca}^{2+}$ was removed during nicotine pretreatment. Cells were treated in $\mathrm{HBS} 0.3\left(0 \mathrm{~mm} \mathrm{CaCl}, 3 \mathrm{~mm} \mathrm{MgCl}_{2}\right)$ with or without $10 \mu \mathrm{M}$ nicotine and then assayed for changes in $\mathrm{Ca}^{2+}$ in $\mathrm{HBS}$ 2.1. Control cells were treated with $\mathrm{HBS}$ 2.1 for $1 \mathrm{hr}$ before assaying for glutamate response $(n=3) . b$, Coincubation with $50 \mu \mathrm{m}$ nifedipine (NIC/NIF) reversed the ability of nicotine $(10 \mu \mathrm{m})$ to alter glutamate-mediated $\mathrm{Ca}^{2+}$ entry $(n=4)$. Data are shown as mean \pm SEM.

$\mathrm{Ca}^{2+}$ entry. L-type $\mathrm{Ca}^{2+}$ channels were blocked with $50 \mu \mathrm{M}$ nifedipine during nicotine pretreatment, nifedipine was washed out, and cells were loaded with fluo- 3 and treated with glutamate. Coincubation with nicotine and nifedipine significantly reduced the effect of nicotine on subsequent glutamate-mediated $\mathrm{Ca}^{2+}$ influx compared with nicotine pretreatment alone (Fig. $3 b$ ). We cannot rule out that $50 \mu \mathrm{M}$ nifedipine may act as an $\mathrm{nAChR}$ channel blocker, but it is likely that the predominant effect during pretreatment is on $\mathrm{Ca}^{2+}$ channel blockade (Tsuneki et al., 2000). In addition, a small amount of nifedipine may still be present during glutamate treatment, but this concentration is likely to be below the $K_{\mathrm{i}}$ for L-type channel antagonism. Nifedipine is a reversible channel blocker and, thus, is not likely to result in a persistent blockade of L-type channels after washout. Together, these studies demonstrate the importance of $\mathrm{Ca}^{2+}$ entry during nicotine treatment for its subsequent effects on glutamatemediated $\mathrm{Ca}^{2+}$ entry. In addition, these studies identify a role for nAChR and L-type $\mathrm{Ca}^{2+}$ channels during the nicotine preincubation period.

The ability of nicotine to decrease glutamate-mediated $\mathrm{Ca}^{2+}$ entry was absent in $\beta 2-/-$ cultures, suggesting that high-affinity nAChRs are critical for this effect (Fig. $4 a, b$ ). The $\alpha 7$-selective antagonist $\alpha$-BTX (100 nM) was added to wild-type and $\beta 2-/-$ cultures to examine the possible contribution of the $\alpha 7 \mathrm{nAChR}$. Whereas glutamate-mediated $\mathrm{Ca}^{2+}$ influx was reduced significantly by nicotine pretreatment, coincubation with nicotine and $\alpha$-BTX resulted in an intermediate $\mathrm{Ca}^{2+}$ response to glutamate that was not significantly different from HBS-treated $(p>0.1)$ or nicotine-treated $(p>0.3)$ cultures (Fig. $4 c, e)$. Coincubation of $\beta 2-/-$ cultures with nicotine and $\alpha$-BTX did not significantly alter $\mathrm{Ca}^{2+}$ response to glutamate compared with nicotine pretreatment alone $(p>0.06)$, although there was a trend toward a small decrease in $\mathrm{Ca}^{2+}$ levels compared with nicotine alone that could reflect a role for $\alpha 7 \mathrm{nAChRs}$ in this effect (Fig. $4 d, f$ ).

Next, we determined whether ionotropic glutamate receptors, $\mathrm{Ca}^{2+}$ channels, or internal stores were sources for glutamatemediated increases in intracellular $\mathrm{Ca}^{2+}$. Cadmium $(200 \mu \mathrm{M})$ increased basal fluorescence but abolished $\mathrm{Ca}^{2+}$ influx with glutamate stimulation (Fig. 5a). At the concentration used, cadmium is known to block L-, $\mathrm{P}$-, and T-type $\mathrm{Ca}^{2+}$ channels and to inhibit NMDA receptors but not AMPA or kainate receptors (Mayer et al., 1989), suggesting that voltage-sensitive $\mathrm{Ca}^{2+}$ channels or NMDA receptors are dominant sources for the cytosolic

a
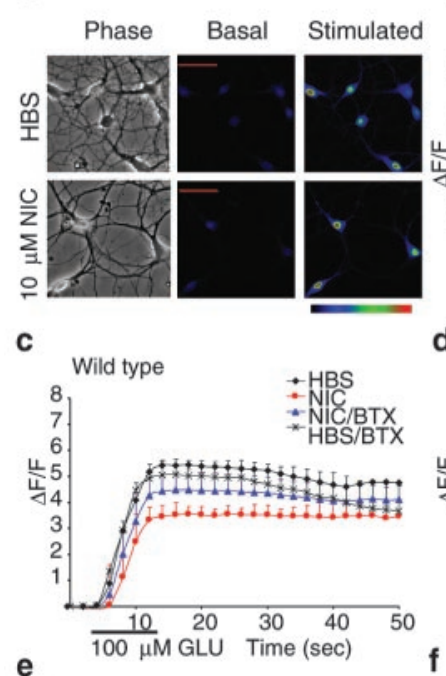

b

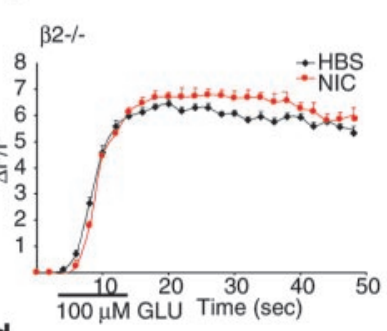

d $\beta 2 \%$
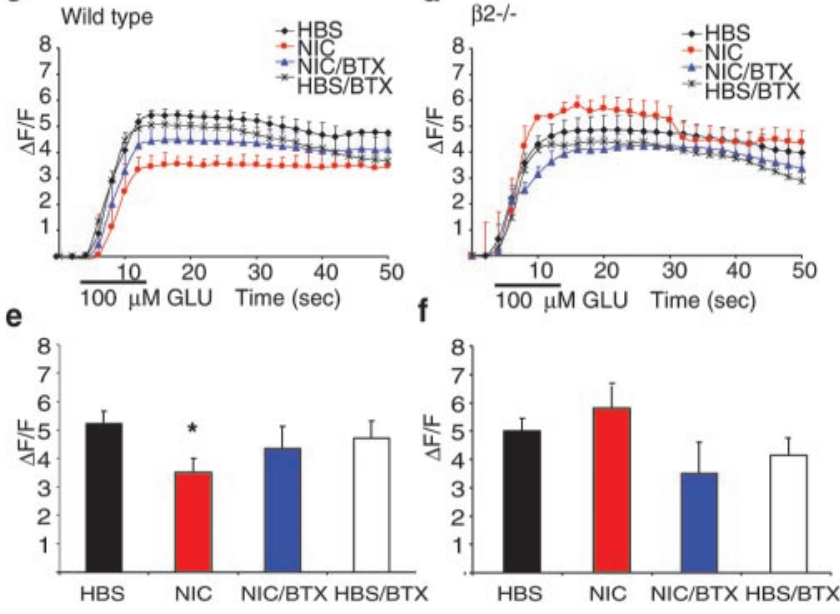

Figure 4. High-affinity $n A C h R s$ are involved in the effect of nicotine on glutamate-mediated $\mathrm{Ca}^{2+}$ entry. $a$, Examples of $\beta 2-1-$ cortical neurons at rest or stimulated with $100 \mu \mathrm{m}$ glutamate pretreated with either $10 \mu \mathrm{m}$ nicotine (bottom) or HBS (top). Phase contrast images of respective fields are shown on the left. Scale bar, $50 \mu \mathrm{m} . b$, Quantitation of glutamatemediated $\mathrm{Ca}^{2+}$ influx in $\beta 2-/-$ cultures. Shown are averages from $n=5$ cultures. c, Effect of the $\alpha 7 \mathrm{nAChR}$ blocker $\alpha$-BTX on wild-type cortical neurons. Cultures $(n=4)$ were pretreated with either $\alpha$-BTX or nicotine or coincubated with nicotine and $\alpha$-BTX. Pretreatment with 10 $\mu \mathrm{m}$ nicotine was the only treatment that significantly reduced $\mathrm{Ca}^{2+}$ influx. $d, \alpha$-BTX does not significantly alter $\mathrm{Ca}^{2+}$ influxin cultures from $\beta 2-/-$ mice. The small increase in $\mathrm{Ca}^{2+}$ influx observed in $\beta 2-1-$ cultures treated with nicotine was not significant $(p>0.06 ; n=4) . e$, $f$, Average $\Delta F / F$ for each treatment from 20 to 40 sec for wild-type and knock-out cultures. NIC, Nicotine; GLU, glutamate. ${ }^{*} p<0.05$. Data are shown as mean \pm SEM.

$\mathrm{Ca}^{2+}$ increase in response to glutamate. A $50 \mu \mathrm{M}$ concentration of NBQX, a blocker of AMPA-type glutamate receptors, did not alter glutamate-dependent $\mathrm{Ca}^{2+}$ entry, suggesting that AMPA channels do not play a substantial role in glutamate-evoked $\mathrm{Ca}^{2+}$ entry in cortical cultures (Fig. 5b). In contrast, treatment with an NMDA receptor antagonist $(100 \mu \mathrm{M}$ APV) significantly decreased glutamate-mediated $\mathrm{Ca}^{2+}$ influx $(\sim 50 \%)$ (Fig. $\left.4 c\right)$. The specific L-type channel blocker nifedipine $(50 \mu \mathrm{M})$ also resulted in a $\sim 50 \%$ decrease in glutamate-mediated $\mathrm{Ca}^{2+}$ influx (Fig. $5 d$ ). Thus, both NMDA-type glutamate receptors and L-type $\mathrm{Ca}^{2+}$ channels contribute significantly to the $\mathrm{Ca}^{2+}$ influx after glutamate stimulation. Combined treatment with nifedipine and APV did not block all $\mathrm{Ca}^{2+}$ entry attributable to glutamate (Fig. 5e); however, a ryanodine receptor antagonist that blocks release of $\mathrm{Ca}^{2+}$ from intracellular stores (50 $\mu \mathrm{M}$ dantrolene) caused a decrease in glutamate-stimulated $\mathrm{Ca}^{2+}$ entry that was similar in magnitude to the residual $\mathrm{Ca}^{2+}$ after nifedipine and APV treatment (Fig. 5f). Together, these data suggest that glutamate treatment in cortical neurons results in activation of L-type $\mathrm{Ca}^{2+}$ channels and NMDA receptors as well as in release of $\mathrm{Ca}^{2+}$ from intracellular stores through ryanodine receptors. APV and dantrolene did not change the ability of nicotine to inhibit glutamateinduced $\mathrm{Ca}^{2+}$ influx, because each agent, when combined with nicotine pretreatment, significantly attenuated the response to 
a
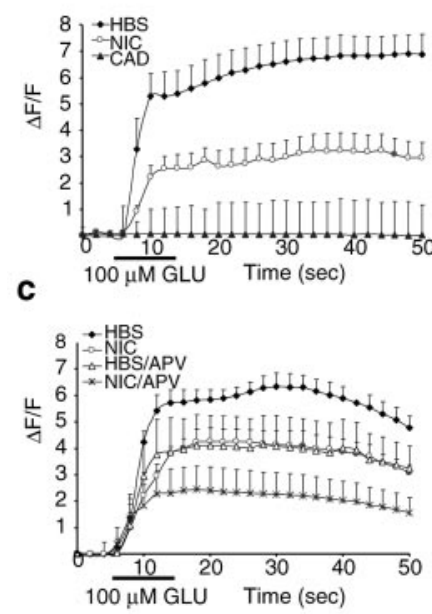

e

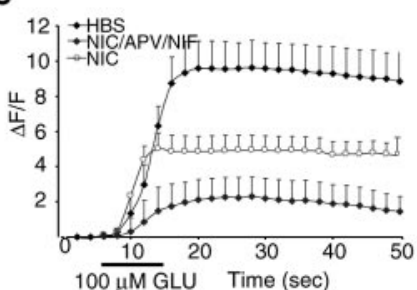

f

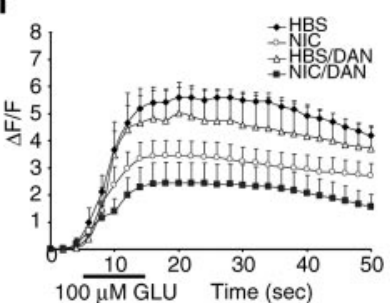

b
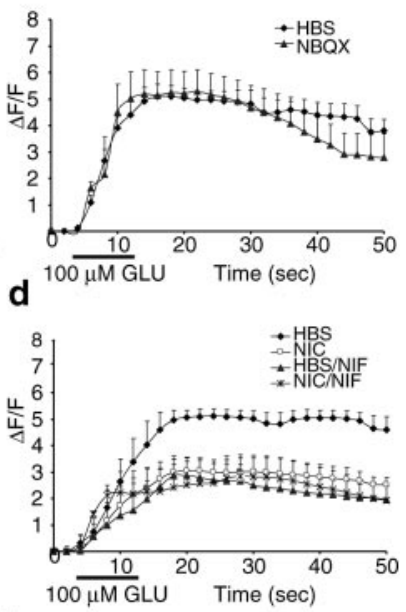

4

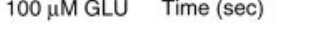

Figure 5. Nicotine pretreatment abolishes glutamate-induced $\mathrm{Ca}^{2+}$ entry through L-type $\mathrm{Ca}^{2+}$ channels. $a, \mathrm{~A} 200 \mu \mathrm{m}$ concentration of cadmium (CAD) abolished glutamate-mediated $\mathrm{Ca}^{2+}$ influx $(n=3) . b, \mathrm{~A} 50 \mu \mathrm{m}$ concentration of NBQX had no effect on $\mathrm{Ca}^{2+}$ influx, suggesting that AMPA currents do not contribute to glutamate-mediated $\mathrm{Ca}^{2+}$ entry in neurons. $C, A$ $100 \mu \mathrm{m}$ concentration of APV decreased glutamate-evoked $\mathrm{Ca}^{2+}$ influx by $50 \%$ (HBS/APV). Nicotine and APV inhibition of $\mathrm{Ca}^{2+}$ entry was additive (NIC/APV). NIC/APV was significantly different from HBS, NIC, and HBS/APV treatment $(n=4)$. d, A $50 \mu \mathrm{m}$ concentration of nifedipine (HBS/NIF) significantly reduced glutamate-mediated $\mathrm{Ca}^{2+}$ influx. Nifedipine did not further reduce the glutamate-mediated $\mathrm{Ca}^{2+}$ entry after nicotine pretreatment (NIC/NIF) $(n=4)$. $e$, A residual glutamate-mediated $\mathrm{Ca}^{2+}$ influx was observed when both NMDA receptors and L-type channels were blocked, most likely because of internal stores $(n=3) . f$, A $50 \mu$ m concentration of dantrolene (HBS/DAN) decreased glutamate-mediated $\mathrm{Ca}^{2+}$ influx slightly but significantly $(n=4)$. The effects of nicotine and dantrolene (NIC/DAN) on glutamate-mediated $\mathrm{Ca}^{2+}$ entry were additive. ${ }^{*} p<0.05$ using LSD post hoc test. Data are shown as mean \pm SEM.

glutamate compared with nicotine pretreatment alone (Fig. $5 c, e$ ). In contrast, nicotine occluded the inhibition of glutamateevoked $\mathrm{Ca}^{2+}$ entry by nifedipine (Fig. $5 d$ ), suggesting that nicotine pretreatment decreases the activity of L-type $\mathrm{Ca}^{2+}$ channels in cortical neurons.

L-type channels can be inactivated by the $\mathrm{Ca}^{2+}$-dependent phosphatase calcineurin (Hernandez-Lopez et al., 2000; Day et al., 2002). We therefore examined whether inhibition of calcineurin could abolish the nicotine-mediated decrease in $\mathrm{Ca}^{2+}$ influx. Preincubation with nicotine and FK506 (100 nM), a calcineurin inhibitor, completely abolished the subsequent decrease in glutamate-mediated $\mathrm{Ca}^{2+}$ influx (Fig. 6a). Coincubation with FK506 (100 nM) during the pretreatment period also blocked the protective effect of nicotine (Fig. $6 b$ ). In contrast, neurons pretreated with nicotine for $1 \mathrm{hr}$ and then subsequently treated with FK506 and glutamate showed intact nicotine-mediated neuroprotection. Finally, treatment with FK506 alone, which continued through the period of glutamate application, was neuroprotective. Thus, calcineurin activation before glutamate treatment (as is achieved by nicotine pretreatment) is neuroprotective. In contrast, once glutamate is present, calcineurin blockade is neu-

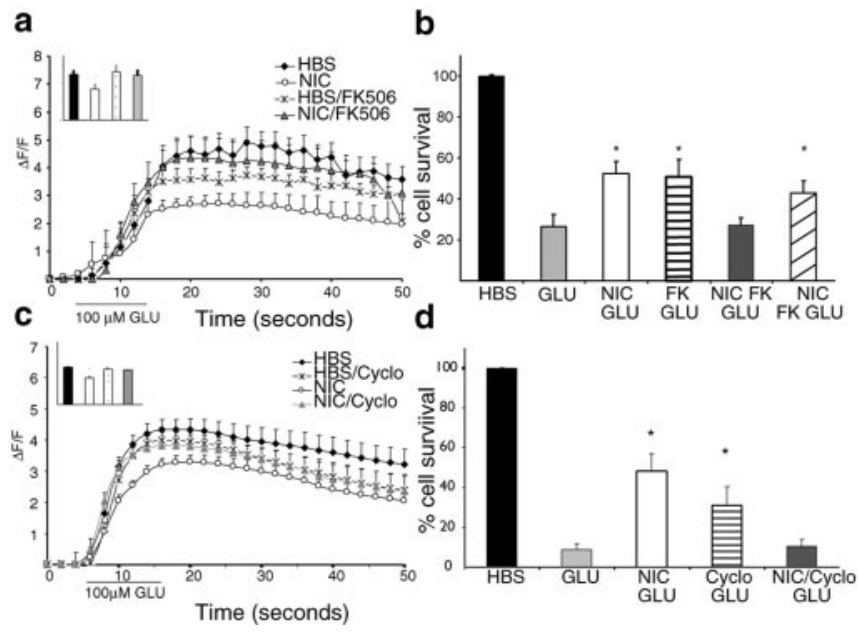

Figure 6. Blockade of calcineurin counteracts the effects of nicotine (NIC) on glutamate (GLU)-mediated $\mathrm{Ca}^{2+}$ entry and neuroprotection. $a$, Treatment with FK506 during nicotine preincubation (NIC/FK506) reversed the decrease in glutamate-mediated $\mathrm{Ca}^{2+}$ influx observed with nicotine pretreatment $(n=5)$. $b$, Nicotine (NIC-GLU) and FK506 (FK-GLU) treatment alone were significantly neuroprotective against glutamate toxicity in neurons (cell survival compared with control cultures was 52.2 and $50.6 \%$, respectively) $(p<0.05)$. Cell survival after pretreatment with both nicotine and FK506 (NIC FK-GLU) was not statistically different from glutamate treatment alone. Treatment with nicotine and subsequently with FK506 plus glutamate showed a level of neuroprotection equivalent to nicotine treatment alone $(n=5)$.c, Treatment with cyclosporine $(1 \mu \mathrm{m})$ during nicotine preincubation reversed the decrease in glutamate-mediated $\mathrm{Ca}^{2+}$ influx observed with nicotine pretreatment $(n=6)$. $d$, Coincubation with nicotine and cyclosporine ( $\mathrm{NIC/Cyclo)} \mathrm{significantly} \mathrm{attenuated} \mathrm{nicotine-mediated}$ neuroprotection. The peak values for each curve were used for ANOVA (12-22 sec). Post hoc analyses were conducted when appropriate using the LSD test. ${ }^{*} p<0.05$. Data are shown as mean \pm SEM.

roprotective. To verify the specificity of the involvement of calcineurin in the effects of nicotine, these experiments were repeated using a second calcineurin blocker, cyclosporine. Coincubation with $10 \mu \mathrm{M}$ nicotine and $1 \mu \mathrm{M}$ cyclosporine completely abolished the subsequent decrease in glutamate-mediated $\mathrm{Ca}^{2+}$ influx (Fig. 6c). Like FK506, pretreatment with cyclosporine $(1 \mu \mathrm{M})$ for $1 \mathrm{hr}$ before glutamate treatment was neuroprotective, but coincubation blocked the protective effect of nicotine (Fig. 6d). Thus, both cyclosporine and FK506 treatment abolished the decrease in glutamate-mediated $\mathrm{Ca}^{2+}$ entry attributable to nicotine and also reversed nicotine-mediated neuroprotection. This suggests that the neuroprotective effects of nicotine might be mediated through calcineurin-dependent inactivation of L-type $\mathrm{Ca}^{2+}$ channels.

\section{Discussion}

The mechanisms underlying nicotine-mediated neuroprotection from glutamate excitotoxicity were investigated in this study. We demonstrate that nicotine pretreatment reduces glutamatemediated $\mathrm{Ca}^{2+}$ influx into cortical neurons and identify a signaling pathway leading from nicotine treatment to decreased glutamatemediated excitotoxicity (Fig. 7). Nicotine treatment activates $\mathrm{nAChRs} \mathrm{(including} \beta 2$ subunit-containing receptors); influx of low levels of $\mathrm{Ca}^{2+}$ during this treatment might occur directly through nAChRs but also occurs indirectly through activation of voltagegated $\mathrm{Ca}^{2+}$ channels. $\mathrm{Ca}^{2+}$ influx activates calcineurin, which has been shown to decrease L-type $\mathrm{Ca}^{2+}$ channel activity (Lukyanetz et al., 1998; Day et al., 2002). This L-type channel inactivation results in decreased $\mathrm{Ca}^{2+}$ entry into the neuron with glutamate stimulation, which might decrease excitotoxicity.

Several studies have identified biochemical responses to nico- 
tine that might contribute to its neuroprotective effects, including increased levels of neuronal growth factors (Belluardo et al., 2000), decreased nitric oxide generation (Shimohama et al., 1996), decreased arachidonic acid release (Marin et al., 1997), activation of akt kinase (Kihara et al., 2001), and decreased caspase signaling (Meyer et al., 2002). However, a direct link between these pathways and nicotinemediated neuroprotection has yet to be identified. The experiments described here show that high-affinity nicotinic receptors containing the $\beta 2$ subunit are required for decreased glutamate-mediated $\mathrm{Ca}^{2+}$ entry. Both in vivo and in vitro studies have shown that $\alpha 4 / \beta 2^{\star} \mathrm{nAChRs}$ contribute to the neuroprotective effects of nicotine. For example, mice lacking the $\alpha 4$ subunit of the nAChR do not show the neuroprotective effects of nicotine against methamphetamine-induced neurodegeneration in striatal neurons (Ryan et al., 2001). Similarly, $\alpha 4 / \beta 2$-type nAChRs are required for nicotine-induced neuroprotection against neonatal ibotenic acid lesion of the cortex (Laudenbach et al., 2002). We propose that the mechanisms reported here could also explain nicotine-induced neuroprotection against methamphetamine or ibotenate neurotoxicity.

Our data are consistent with a cooperative involvement of $\beta 2$ subunit-containing and $\alpha 7 \mathrm{nAChRs}$ in the neuroprotective effects of nicotine. One possible explanation for these data are that $\alpha 7$-containing nAChRs are critical for direct $\mathrm{Ca}^{2+}$ influx, whereas $\beta 2$ subunit-containing $\mathrm{nAChRs}$ are required for depolarization and subsequent activation of voltage-gated $\mathrm{Ca}^{2+}$ channels. Recent reports also suggest that $\alpha 7$ and $\beta 2$ can form functional heteromeric nAChRs (Khiroug et al., 2002). However, the mechanisms of $\beta 2$ - and $\alpha 7$-mediated neuroprotection appear to be at least somewhat distinct. Knock-out of the $\beta 2$ subunit abolished the effect of nicotine on glutamate-mediated $\mathrm{Ca}^{2+}$ entry, whereas $\alpha$-bungarotoxin treatment did not alter this effect significantly. This is consistent with previous studies showing that $\alpha 7$ mediated neuroprotection in the hippocampus did not involve alteration of glutamate-mediated $\mathrm{Ca}^{2+}$ entry (Dajas-Bailador et al., 2000). The effect of $\alpha 7$ on nicotine-mediated neuroprotection might be downstream of $\mathrm{Ca}^{2+}$ entry and might involve activation of the MAP kinase cascade (Dajas-Bailador et al., 2002). Our data suggest that more than one subtype of $\mathrm{nAChR}$ is involved in the neuroprotective effects of nicotine, and the contribution of each subtype might depend on the type of cytotoxic insult, the region of the brain studied, and the neuronal types involved.

The data presented here suggest that nicotine acting through $\beta 2$ subunit-containing $\mathrm{nAChRs}$ activates calcineurin and leads to inactivation of L-type $\mathrm{Ca}^{2+}$ channels. A role for calcineurin as a downstream mediator of $\mathrm{nAChR}$ stimulation is plausible, because calcineurin is activated by low levels of $\mathrm{Ca}^{2+}$ (Yakel, 1997). After nicotine treatment, nAChRs are activated and desensitized rapidly; however, after desensitization, there is a significantly reduced response to nicotine that is not abolished (Fenster et al., 1999). Thus, nAChR stimulation is likely to result in a low level of $\mathrm{Ca}^{2+}$ entry that can activate a high-affinity $\mathrm{Ca}^{2+}$ sensor (calcineurin) but is less able to activate low-affinity $\mathrm{Ca}^{2+}$ sensors (such as the $\mathrm{Ca}^{2+}$-dependent kinases) (Lisman, 1989).

Consistent with this possibility, we have shown that inhibition of calcineurin blocks the effects of nicotine on glutamate-evoked $\mathrm{Ca}^{2+}$ influx through L-type channels and abolishes the protective effect of nicotine in cortical neurons. The effect of nicotine on glutamate-mediated $\mathrm{Ca}^{2+}$ entry is already seen after 5 min of nicotine pretreatment and is sustained after $1 \mathrm{hr}$ of nicotine treatment. In contrast, cotreatment with nicotine and glutamate did not result in a change in glutamate-mediated $\mathrm{Ca}^{2+}$ entry, suggesting that nicotinic activation of calcineurin only during the period when glutamate is present is not sufficient to result in changes in $\mathrm{Ca}^{2+}$ influx.

FK506 and cyclosporine, when present during glutamate exposure, were protective against excitotoxicity, as has been seen in several other studies (H. G. Wang et al., 1999; Guo et al., 2001); in contrast, cotreatment with FK506 or cyclosporine and nicotine during the $1 \mathrm{hr}$ before glutamate exposure results in blockade of the protective effects of nicotine against excitotoxicity. This suggests that calcineurin has a differential role in neuroprotection in the period before exposure to an excitotoxic agent and during the period the agent is present. Similar paradoxical observations have been made using tumor necrosis factor- $\alpha$ and nicotine (Carlson et al., 1998). The actions of calcineurin extend well beyond regulation of L-type $\mathrm{Ca}^{2+}$ channels. For example, calcineurin increases the activity of nitric oxide synthase (Dawson et al., 1993), an effector implicated in events downstream of nicotine-induced neuroprotection (Shimohama et al., 1996), dephosphorylates and activates the proapoptotic protein BAD (Bcl-2-associated death protein) (H. G. Wang et al., 1999), and downregulates NMDA receptors (Shi et al., 2000). Phosphorylation of BAD can be either neuroprotective (H. X. Wang et al., 1999) or proapoptotic (Konishi et al., 2002), depending on the site of phosphorylation, suggesting another point for differential regulation of neuroprotection by calcineurin. Given the multitude of effectors downstream of calcineurin (potentially including nAChRs), it is conceivable that different levels or temporospatial patterns of calcineurin activity modulate signaling cascades that have either neuroprotective or neurotoxic effects.

These studies show that nicotine treatment modulates glutamate signaling in cortical neurons through activation of calcineurin. Both glutamate receptors and calcineurin are known to be critical for changes in synaptic strength such as long-term potentiation and long-term depression (Malenka and Nicoll, 1999; Riedel, 1999). Thus, although the current studies have focused on a mechanism underlying nicotine-mediated neuroprotection, the signal transduction pathways delineated here could also be responsible for effects of nicotine on plastic processes, such as learning or addiction.

\section{References}

Akaike A, Tamura Y, Yokota T, Shimohama S, Kimura J (1994) Nicotineinduced protection of cultured cortical neurons against $N$-methylD-aspartate receptor-mediated glutamate cytotoxicity. Brain Res 644:181-187. 
Belluardo N, Mudo G, Blum M, Fuxe K (2000) Central nicotinic receptors, neurotrophic factors and neuroprotection. Behav Brain Res 113:21-34.

Borlongan CV, Shytle RD, Ross SD, Shimizu T, Freeman TB, Cahill DW, Sanberg PR (1995) Nicotine protects against systemic kainic acidinduced excitotoxic effects. Exp Neurol 136:261-265.

Carlson NG, Bacchi A, Rogers SW, Gahring LC (1998) Nicotine blocks TNF-alpha-mediated neuroprotection to NMDA by an alphabungarotoxin-sensitive pathway. J Neurobiol 35:29-36.

Chang KT, Berg DK (2001) Voltage-gated channels block nicotinic regulation of CREB phosphorylation and gene expression in neurons. Neuron 32:855-865.

Dajas-Bailador FA, Lima PA, Wonnacott S (2000) The alpha7 nicotinic acetylcholine receptor subtype mediates nicotine protection against NMDA excitotoxicity in primary hippocampal cultures through a $\mathrm{Ca}(2+)$ dependent mechanism. Neuropharmacology 39:2799-2807.

Dajas-Bailador FA, Soliakov L, Wonnacott S (2002) Nicotine activates the extracellular signal-regulated kinase $1 / 2$ via the alpha7 nicotinic acetylcholine receptor and protein kinase A, in SH-SY5Y cells and hippocampal neurones. J Neurochem 80:520-530.

Damaj MI, Welch SP, Martin BR (1993) Involvement of calcium and L-type channels in nicotine-induced antinociception. J Pharmacol Exp Ther 266:1330-1338.

Dawson TM, Steiner JP, Dawson VL, Dinerman JL, Uhl GR, Snyder SH (1993) Immunosuppressant FK506 enhances phosphorylation of nitric oxide synthase and protects against glutamate neurotoxicity. Proc Natl Acad Sci USA 90:9808-9812.

Day M, Olson PA, Platzer J, Striessnig J, Surmeier DJ (2002) Stimulation of $5-\mathrm{HT}(2)$ receptors in prefrontal pyramidal neurons inhibits $\mathrm{Ca}(\mathrm{v}) 1.2 \mathrm{~L}$ type $\mathrm{Ca}(2+)$ currents via a PLCbeta/IP3/calcineurin signaling cascade. J Neurophysiol 87:2490-2504.

Fenster CP, Beckman ML, Parker JC, Sheffield EB, Whitworth TL, Quick MW, Lester RA (1999) Regulation of alpha4beta2 nicotinic receptor desensitization by calcium and protein kinase C. Mol Pharmacol 55:432-443.

Fratiglioni L, Wang HX (2000) Smoking and Parkinson's and Alzheimer's disease: review of the epidemiological studies. Behav Brain Res 113:117-120.

Girod R, Jareb M, Moss J, Role L (2003) Mapping of presynaptic nicotinic acetylcholine receptors using fluorescence imaging of neuritic calcium. J Neurosci Methods 122:109-122.

Guo X, Dillman III JF, Dawson VL, Dawson TM (2001) Neuroimmunophilins: novel neuroprotective and neuroregenerative targets. Ann Neurol 50:6-16.

Hernandez-Lopez S, Tkatch T, Perez-Garci E, Galarraga E, Bargas J, Hamm H, Surmeier DJ (2000) D2 dopamine receptors in striatal medium spiny neurons reduce L-type $\mathrm{Ca}^{2+}$ currents and excitability via a novel PLC $\beta 1$ IP3-calcineurin-signaling cascade. J Neurosci 20:8987-8995.

Jones S, Sudweeks S, Yakel JL (1999) Nicotinic receptors in the brain: correlating physiology with function. Trends Neurosci 22:555-561.

Kaneko S, Maeda T, Kume T, Kochiyama H, Akaike A, Shimohama S, Kimura J (1997) Nicotine protects cultured cortical neurons against glutamateinduced cytotoxicity via alpha7-neuronal receptors and neuronal CNS receptors. Brain Res 765:135-140.

Khiroug SS, Harkness PC, Lamb PW, Sudweeks SN, Khiroug L, Millar NS, Yakel JL (2002) Rat nicotinic ACh receptor alpha7 and beta2 subunits co-assemble to form functional heteromeric nicotinic receptor channels. J Physiol (Lond) 540:425-434.

Kihara T, Shimohama S, Urushitani M, Sawada H, Kimura J, Kume T, Maeda T, Akaike A (1998) Stimulation of alpha-4-beta-2 nicotinic acetylcholine receptors inhibits beta-amyloid toxicity. Brain Res 792:331-334.

Kihara T, Shimohama S, Sawada H, Honda K, Nakamizo T, Shibasaki H, Kume T, Akaike A (2001) Alpha 7 nicotinic receptor transduces signals to phosphatidylinositol 3-kinase to block A beta-amyloid-induced neurotoxicity. J Biol Chem 276:13541-13546.

Konishi Y, Lehtinen M, Donovan N, Bonni A (2002) Cdc2 phosphorylation of BAD links the cell cycle to the cell death machinery. Mol Cell 9:1005-1016.

Laudenbach V, Medja F, Zoli M, Rossi F, Evrard P, Changeux J, Gressens P (2002) Selective activation of central subtypes of the nicotinic acetylcholine receptor has opposite effects on neonatal excitotoxic brain injuries. FASEB J 16:423-435.

Lisman J (1989) A mechanism for the Hebb and the anti-Hebb processes underlying learning and memory. Proc Natl Acad Sci USA 86:9574-9578.

Lukyanetz EA, Piper TP, Sihra TS (1998) Calcineurin involvement in the regulation of high-threshold Ca2 + channels in NG108-15 (rodent neuroblastoma $\times$ glioma hybrid) cells. J Physiol (Lond) 510:371-385.

Malenka RC, Nicoll RA (1999) Long-term potentiation-a decade of progress? Science 285:1870-1874.

Marin P, Maus M, Desagher S, Glowinski J, Premont J (1994) Nicotine protects cultured striatal neurones against $N$-methyl-D-aspartate receptormediated neurotoxicity. NeuroReport 5:1977-1980.

Marin P, Hamon B, Glowinski J, Premont J (1997) Nicotine-induced inhibition of neuronal phospholipase A2. J Pharmacol Exp Ther 280:1277-1283.

Mayer ML, Vyklicky Jr L, Westbrook GL (1989) Modulation of excitatory amino acid receptors by group IIB metal cations in cultured mouse hippocampal neurones. J Physiol (Lond) 415:329-350.

McGehee DS, Role LW (1996) Presynaptic ionotropic receptors. Curr Opin Neurobiol 6:342-349.

Meyer EL, Gahring LC, Rogers SW (2002) Nicotine preconditioning antagonizes activity-dependent caspase proteolysis of a glutamate receptor. J Biol Chem 277:10869-10875.

Picciotto MR, Zoli M, Léna C, Bessis A, Lallemand Y, LeNovčre N, Vincent P, Pich EM, Brulet P, Changeux JP (1995) Abnormal avoidance learning in mice lacking functional high-affinity nicotine receptor in the brain. Nature 374:65-67.

Picciotto MR, Caldarone BJ, Brunzell DH, Zachariou V, Stevens TR, King SL (2001) Neuronal nicotinic acetylcholine receptor subunit knockout mice: physiological and behavioral phenotypes and possible clinical implications. Pharmacol Ther 92:89-108.

Rezvani AH, Levin ED (2001) Cognitive effects of nicotine. Biol Psychiatry 49:258-267.

Riedel G (1999) If phosphatases go up, memory goes down. Cell Mol Life Sci 55:549-553.

Ryan RE, Ross SA, Drago J, Loiacono RE (2001) Dose-related neuroprotective effects of chronic nicotine in 6-hydroxydopamine treated rats, and loss of neuroprotection in alpha4 nicotinic receptor subunit knockout mice. Br J Pharmacol 132:1650-1656.

Sharma G, Vijayaraghavan S (2001) Nicotinic cholinergic signaling in hippocampal astrocytes involves calcium-induced calcium release from intracellular stores. Proc Natl Acad Sci USA 98:4148-4153.

Shi J, Townsend M, Constantine-Paton M (2000) Activity-dependent induction of tonic calcineurin activity mediates a rapid developmental downregulation of NMDA receptor currents. Neuron 28:103-114.

Shieh PB, Hu SC, Bobb K, Timmusk T, Ghosh A (1998) Identification of a signaling pathway involved in calcium regulation of BDNF expression. Neuron 20:727-740.

Shimohama S, Akaike A, Kimura J (1996) Nicotine-induced protection against glutamate cytotoxicity. Nicotinic cholinergic receptor-mediated inhibition of nitric oxide formation. Ann NY Acad Sci 777:356-361.

Shoop RD, Chang KT, Ellisman MH, Berg DK (2001) Synaptically driven calcium transients via nicotinic receptors on somatic spines. J Neurosci 21:771-781.

Shoop RD, Esquenazi E, Yamada N, Ellisman MH, Berg DK (2002) Ultrastructure of a somatic spine mat for nicotinic signaling in neurons. J Neurosci 22:748-756.

Tao X, Finkbeiner S, Arnold DB, Shaywitz AJ, Greenberg ME (1998) Ca2+ influx regulates BDNF transcription by a CREB family transcription factor-dependent mechanism. Neuron 20:709-726.

Tsuneki H, Klink R, Léna C, Korn H, Changeux JP (2000) Calcium mobilization elicited by two types of nicotinic acetylcholine receptors in mouse substantia nigra pars compacta. Eur J Neurosci 12:2475-2485.

Vijayaraghavan S, Pugh PC, Zhang ZW, Rathouz MM, Berg DK (1992) Nicotinic receptors that bind alpha-bungarotoxin on neurons raise intracellular free Ca2+. Neuron 8:353-362.

Wang HG, Pathan N, Ethell IM, Krajewski S, Yamaguchi Y, Shibasaki F, McKeon F, Bobo T, Franke TF, Reed JC (1999) Ca2+-induced apoptosis through calcineurin dephosphorylation of BAD. Science 284:339-343.

Wang HX, Fratiglioni L, Frisoni GB, Viitanen M, Winblad B (1999) Smoking and the occurrence of Alzheimer's disease: cross-sectional and longitudinal data in a population-based study. Am J Epidemiol 149:640-644.

Yakel JL (1997) Calcineurin regulation of synaptic function: from ion channels to transmitter release and gene transcription. Trends Pharmacol Sci $18: 124-134$.

Zoli M, Picciotto MR, Ferrari R, Cocchi D, Changeux JP (1999) Increased neurodegeneration during ageing in mice lacking high-affinity nicotine receptors. EMBO J 18:1235-1244. 